\title{
Toward a goal-oriented view of customer journeys
}

\author{
Larissa Becker, Elina Jaakkola and Aino Halinen \\ Department of Marketing and International Business, \\ Turku School of Economics, University of Turku, Turku, Finland
}

\begin{abstract}
Purpose - Customer experience research predominantly anchors the customer journey on a specific offering, implying an inherently firm-centric perspective. Attending calls for a more customer-centric approach, this study aims to develop a goal-oriented view of customer journeys.

Design/methodology/approach - This study interprets the results of a phenomenological study of a transformative journey toward a sober life with the self-regulation model of behavior to advance understanding of customer journeys.

Findings - The consumer's journey toward a higher-order goal encompasses various customer journeys toward subordinate goals, through which consumers engage in iterative cognitive and behavioral processes to adjust or maintain their experienced situation vis-à-vis the goal. Experiences drive behavior toward the goal. It follows that negative experiences may contribute to goal attainment.

Research limitations/implications - This study highlights the importance of looking at the consumers' higher-order goals to obtain a more holistic understanding of the customer journey.

Practical implications - Companies and organizations should extend their view beyond the immediate goals of their customers to identify relevant touchpoints and other customer journeys that affect the customer experience.

Originality/value - This study proposes conceptualization of the customer journey, comprising goal-oriented processes at different hierarchical levels, and it demonstrates how positive and negative customer experiences spur behaviors toward the higher-order consumer goal. This conceptualization enables a more customercentric perspective on journeys.
\end{abstract}

Keywords Customer experience, Customer journey, Consumer journey, Self-regulation model, Goals

Paper type Research paper

\section{Introduction}

The customer journey has become one of the key concepts for service and marketing research (e.g. Becker and Jaakkola, 2020; Lemon and Verhoef, 2016). Customer journeys are commonly defined as a series of touchpoints that customers go through before, during and after purchase (Kranzbühler et al., 2018; Lemon and Verhoef, 2016; Patrício et al., 2011). Practitioners' and academics' increasing interest in the concept is largely attributable to the notion that journeys give rise to customer experience, which is considered a key source of competitive advantage in today's markets (e.g. Kranzbühler et al., 2018). Customer experience refers to the customer's sensorial, affective, cognitive, relational and behavioral responses and reactions to various stimuli along the customer journey (Følstad and Kvale, 2018; Lemon and Verhoef, 2016). Hence, understanding customer journeys is a prerequisite for developing superior customer experiences (Følstad and Kvale, 2018; Kuehnl et al., 2019).

(C) Larissa Becker, Elina Jaakkola and Aino Halinen. Published by Emerald Publishing Limited. This article is published under the Creative Commons Attribution (CC BY 4.0) licence. Anyone may reproduce, distribute, translate and create derivative works of this article (for both commercial and noncommercial purposes), subject to full attribution to the original publication and authors. The full terms of this licence may be seen at http://creativecommons.org/licences/by/4.0/legalcode.

The authors thank Associate Professor Lia Patrício, Professor Emma Macdonald, two anonymous Reviewers as well as the Editor and the Guest Editor for their valuable comments to this article.

Funding: This project was funded by the Foundation for Economic Education (Liikesivistysrahasto).
A goal-oriented view of customer journeys

Received 4 November 2019 Revised 16 April 2020 3 June 2020

4 June 2020

Accepted 11 June 2020

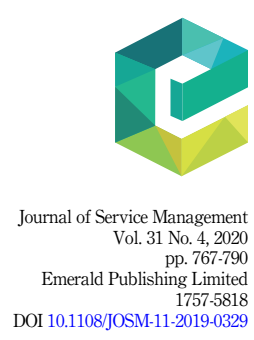


JOSM 31,4

768

Extant research nevertheless offers a limited view on customer journeys. Most studies anchor the customer journey on a specific product or service, implying an inherently firmcentric perspective that offers little insight into touchpoints beyond the firm's influence. Recently, there have been calls for a more customer-centric perspective. Heinonen and Strandvik (2015) argued that, in order to understand value creation, the focus should shift from how providers involve customers in their processes to how consumers engage with different types of actors in their lifeworld. Lipkin (2016) suggested adopting a perspective that highlights the consumer's goals, activities and tasks to provide a holistic view of the customer experience. Hamilton and Price (2019) noted that true customer orientation necessitates an understanding of the journeys toward large and small life goals and suggested focusing on the consumer (as opposed to customer) journey to break free from a firm-centric focus.

These suggestions point out the need to examine journeys focused on consumers' goals rather than on a particular purchase or service. Therefore, this study aims to develop a goaloriented view of the customer journey. This view departs from what consumers want to achieve in their lifeworlds and illuminates the consumers' processes toward their higherorder goals, acknowledging that consumers draw on multiple market and nonmarket resources to accomplish them (Epp and Price, 2011; Hamilton and Price, 2019). A goaloriented view thus provides a more customer-centric perspective that has been strongly advocated in service research (e.g. Grönroos and Ravald, 2011; Heinonen et al., 2010; Vargo and Lusch, 2008).

A goal-oriented view on customer journeys could also benefit service practice. It offers a holistic picture of the consumers' processes toward the goal, which likely involve interactions with a range of actors. Through this holistic view, a firm can better understand how its offering fits into these processes, how distinct customer journeys are connected and what elements outside its direct control affect the customer experience. A goal-oriented view of the customer journey can offer firms opportunities to develop compelling solutions (Epp and Price, 2011) and innovations (Patrício et al., 2011) that help their customers achieve their goals, thus facilitating value creation (Hamilton and Price, 2019; Heinonen et al., 2010; Macdonald et al., 2016).

This study poses three specific research questions. First, what is the structure of a goaloriented customer journey? As customer experience research has focused predominantly on the firm or product rather than on consumer goals, the customer journey is typically structured as a series of touchpoints related to the customer's purchase process (Lemon and Verhoef, 2016). Focusing on consumers' higher- and lower-order goals can reveal a more complex, multileveled structure of the journey.

The second research question inquires what processes does a goal-oriented customer journey comprise? So far, the customer journey literature has mainly focused on mapping customer buying behaviors such as information search, consideration, choice and usage (e.g. Edelman and Singer, 2015; Lemon and Verhoef, 2016). However, extant research has not considered the more general goal-related processes that can offer a new understanding of the mechanisms underlying a customer's behaviors during a goal-oriented journey.

Third, what is the relationship between customer experience and consumer goals within the goal-oriented customer journey? The customer experience literature has treated customer experience mainly as a response to stimuli, focusing on its evaluative outcomes vis-à-vis the firm or the brand (e.g. Brakus et al., 2009; Kuehnl et al., 2019; Lemon and Verhoef, 2016). Investigating experiences in relation to the consumer goal pursuit offers a novel, more holistic perspective that has recently been called for (e.g. McColl-Kennedy et al., 2015).

To address these questions, a phenomenological study was conducted to describe consumers' lived experiences as they emerge in a particular context (Thompson et al., 1989). The empirical study focuses on a transformative journey that aims at a significant life 
change: recovery from alcoholism. Both practical relevance and theoretical potential directed this choice. Consumer goals related to health and well-being are of particular importance for both the individual and society. Recovery from alcoholism represents an extreme context that can unveil a rich picture of goal-oriented customer journeys, thus enabling conceptual development.

The phenomenological findings were interpreted using the self-regulation model of behavior (Carver and Scheier, 1998) to offer a new understanding of customer journeys in three major ways. First, furthering the ideas proposed by Hamilton and Price (2019), this study presents a goal-oriented and hierarchical view of journeys that highlights how customer journeys toward lower-order goals involving market, organizational and social actors are embedded into broader consumer journeys toward higher-order goals. Second, this study identifies iterative cognitive and behavioral processes that relate to how consumers set goals and seek to change or maintain the experienced situation in relation to their goals during the journey. Third, the model offers a novel explanation of how the customer experience operates in the customer journey, not merely as an outcome but as a driving force toward the consumer's higher-order goals.

The next section briefly outlines the conceptual background for the study. The subsequent sections present the empirical phenomenological research study and its findings on how recovering alcoholics experience their journey toward a sober life. These findings are next interpreted using the self-regulation model of behavior, followed by a conceptualization of goal-oriented customer journeys explicating their structure, processes and the role of the customer experience. The final section of the paper discusses theoretical and practical implications as well as the study's limitations and suggestions for future research studies.

\section{Theoretical foundations}

\subsection{Customer journey and customer experience: toward a goal-oriented view}

The customer experience literature usually portrays the customer journey as a series of touchpoints that customers interact with during their purchase process (Lemon and Verhoef, 2016). The customer journey consists of prepurchase, purchase and post-purchase phases (Lemon and Verhoef, 2016), comprising various provider-designed touchpoints such as communication and service encounters with the focal firm and its partners, which give rise to the customer experience (Følstad and Kvale, 2018). The current literature also acknowledges customer-owned touchpoints (i.e. customer activities related to an offering beyond the firm's control) and the influence of external actors in a customer's experience with the firm or the offering (Jaakkola et al., 2015; Lemon and Verhoef, 2016). Still, the focus remains largely on how these interactions function as stimuli regarding a particular offering, implying a firmcentric view of the customer journey.

Nonetheless, some studies in the customer experience literature provide a more customercentric perspective that can contribute to a goal-oriented view of customer journeys (Table 1). These studies highlight that a customer's interactions with a firm are not isolated but they are connected to a broader service system. Tax et al. (2013) presented the concept of the service delivery network to capture the multiple firms that, from the customer's perspective, provide an overall and connected service. Similarly, Baron and Harris (2010) offered a method to identify multiple actors that are part of an experience domain. Patrício et al. (2011) and Teixeira et al. (2012) stated that the customer experience can emerge from interactions at three levels: (1) the service encounter or touchpoint; (2) the service system, referring to a customer's journey with a single firm; and (3) the value constellation, referring to a network of service providers that enables a consumer's activity. While these approaches provide a view of the customer journey embedded into the broader service system, they do not explicitly address the consumer's higher-order goals. 
JOSM 31,4

\begin{tabular}{ll} 
Study & $\begin{array}{l}\text { Contributions to a customer-centric } \\
\text { perspective of customer journey }\end{array}$ \\
\hline $\begin{array}{l}\text { Baron and } \\
\text { Harris (2010) }\end{array}$ & $\begin{array}{l}\text { The study offers a method to identify } \\
\text { customer interactions with multiple actors } \\
\text { (vs isolated interactions with a focal firm) in } \\
\text { an experience domain }\end{array}$
\end{tabular}

Patrício et al. (2011)

The study uses an activity-based perspective of customer experience that highlights the embeddedness of customer journeys - referred to as the service system - into the customer's value constellation, formed by multiple service organizations that enable a customer's activity

Teixeira et al. (2012)

Tax et al (2013)

\section{Table 1.}

Studies that have contributed to a customer-centric perspective of customer journeys

Hamilton and The editorial suggests that the customer Price (2019) journey is embedded into consumer journeys toward higher-order goals
How the study differs from the present one

(1) The study does not incorporate the concept of the customer journey

(2) The study does not analyze the role of the customer experience in the journey

(3) The study does not explicitly address the consumer's higher-order goals

(1) The activity-based perspective reveals different aspects (e.g. multiple actors that enable a customer's activity) compared to a goal-based perspective (e.g. cognitive and behavioral processes toward a higher-order goal)

(2) The study focuses on service design for the customer experience

(3) The study does not analyze the role of the customer experience in the journey

(4) The study does not explicitly address the consumer's higher-order goals

(1) The activity-based perspective reveals different aspects compared to a goalbased perspective

(2) The study does not analyze the role of the customer experience in the journey

(3) The study does not explicitly address the consumer's higher-order goals

(1) The study focuses on an overall and connected service as an anchor for the journey, not the consumer goal(s)

(2) The study does not analyze the role of the customer experience in the journey

(1) The study does not analyze the role of the customer experience in the journey
(2) It does not fully conceptualize customer or consumer journeys

Hamilton and Price (2019) directed attention toward what customers are trying to accomplish with their purchases. The authors suggest that the broader consumer journey can be understood through the customer's lower- and higher-order goals: for example, a consumer journey where the goal is to recover from illness (i.e. a higher-order goal) may encompass a customer journey focusing on getting a medication (i.e. a lower-order goal). Combining these perspectives suggests that a goal-oriented customer journey can be viewed as multilayered, comprising superordinate and subordinate journeys toward various goals.

As the customer experience literature has tended to focus on the customer journey (cf. Patrício et al., 2011), the processes that consumers go through are described mainly at this level as well. Lemon and Verhoef (2016), for instance, based their conceptualization of the customer journey on consumer purchase and usage processes: they described consumers' behaviors such as need recognition, payment and usage of a product. Patrício et al. (2011) and Teixeira et al. (2012) expanded their focus beyond the customer journey and recognized the consumer's overall activity, which was decomposed into smaller activities, operations and tasks. For instance, at a higher level, buying a house relates to obtaining information and 
getting a mortgage. These activities can be decomposed into smaller ones (e.g. searching for information about mortgages), which, in turn, can be decomposed into even smaller tasks (e.g. accessing Internet banking) (Patrício et al., 2011). To conclude, the existing journey conceptualizations predominantly focus on specific activities and behaviors related to a purchase, usage process or an overall activity. The underlying, more general goal-related processes and behaviors have not been scrutinized.

Viewing customer journeys from a consumer goals perspective is bound to provide new insights into the customer experience. Extant research mainly studies experiences in terms of the firm or the brand, contributing to customer satisfaction and loyalty intentions (e.g. Brakus et al., 2009; Kuehnl et al., 2019). Some studies take a more customer-centric view and consider actors and activities beyond the customer-firm dyad (e.g. Patrício et al., 2011; Teixeira et al., 2012; Tax et al., 2013). These studies recognize that the customer experience emerges as the customer's responses to versatile stimuli in the consumer's lifeworld, but they do not elaborate on how these experiences relate to the consumer's higher-order goals. As goals are central to the approach of the journeys outlined here, the study discusses this literature next.

\subsection{Goals and the self-regulation model of behavior}

Goals are desired states that individuals intend to attain or avoid through action (Austin and Vancouver, 1996). They are not perceived as static end states but as continuously changing (Carver and Scheier, 1982). Many models try to explain how individuals behave when trying to achieve their goals. One useful model is the self-regulation model of behavior (Carver and Scheier, 1982, 1998), which is suitable for developing a goal-oriented view of the customer journey because it describes the process through which individuals pursue a goal.

The self-regulation model of behavior contains four elements - input function, reference value, comparator and output function - that form the basic unit of the model: the feedback loop (Figure 1) (Carver and Scheier, 1982, 1998). According to Carver and Scheier (1990), individuals manifest the functions of this model as a repeating process when they move toward a goal. The input function refers to the sensor through which individuals perceive their current situation. Adapted to the customer journey context, the input refers to the consumer's perception of his/her present situation where customer experience is one of the

\section{A goal-oriented view of customer journeys}

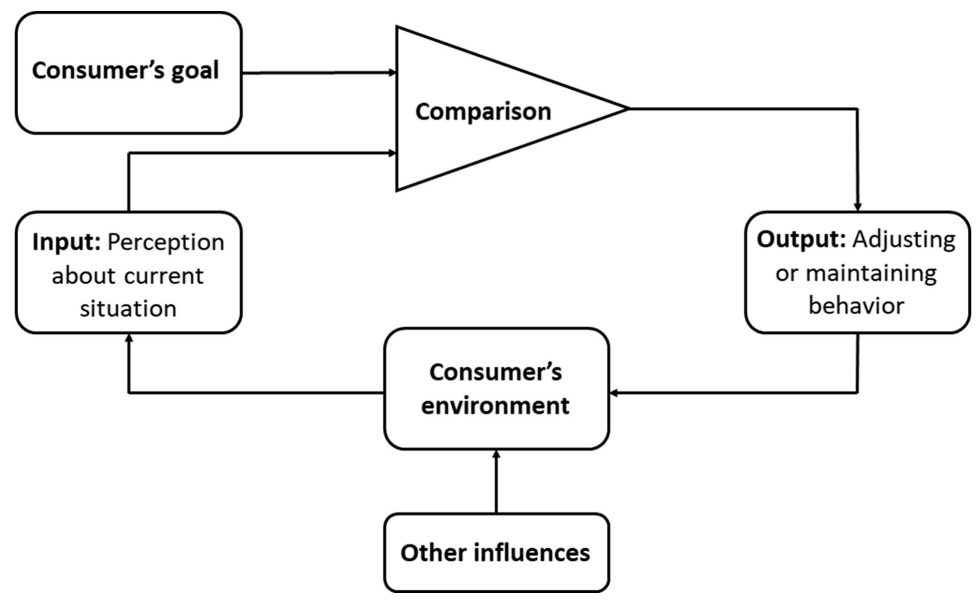

Figure 1.

The feedback loop of the self-regulation model of behavior (adapted from Carver and Scheier, 1982, 1998) 
JOSM 31,4

sources of information about the situation. This perception is compared against a reference value - the consumer's goal, in this context - through a comparator, a mechanism that compares input and the reference value. If there is a discrepancy between the consumer's perception about the current state and the goal, the individual adjusts his/her behavior (output function) to minimize this discrepancy. This change in behavior affects the individual's environment, leading to a new perception of the current situation, compared again with the goal in a repeating fashion. The model also recognizes other influencing factors in an individual's environment (Carver and Scheier, 1982). This means that, even without adjusting their behavior, consumers may experience changes that affect how they perceive their current situation, leading them to behave in a way that counters these disturbances.

This model assumes that goals are organized hierarchically, meaning that lower-level goals are subordinate to higher-order goals (Carver and Scheier, 1982; Powers, 1973). For example, a consumer with the goal of getting healthy (higher-order goal) might have a subordinate goal of buying a medication (lower-level goal) (cf. Hamilton and Price, 2019). These goals vary in their levels of abstraction, from abstract goals at higher levels ("to-be" goals) to more concrete ones at lower levels ("to-do" goals). To move down in the hierarchy, one has to ask "how" to achieve the goal; to move up, one asks "why" (Powers, 1973). The hierarchy does not mean that one achieves a goal on one level to go up or down to another but lower-level goals are ingredients of a higher-level goal (Carver and Scheier, 1998).

In this model, the outputs of higher-order feedback loops provide reference values (i.e. goals) for feedback loops at lower levels (Carver and Scheier, 1982, 1990; Powers, 1973). Feedback loops exist at several levels of the hierarchy - one for each goal (Carver and Scheier, 1982, 1998; Powers, 1973). In this way, this model is also useful for understanding the structure of a goal-oriented customer journey, considering that it is possible to look at different levels of the journey as different feedback loops directed at different levels of goal abstraction.

\section{Methodology}

This study applies a phenomenological research methodology, especially an interpretive (or hermeneutic) tradition that draws on Heidegger's philosophy (e.g. Creswell, 2013; HorriganKelly et al., 2016). Phenomenology "seeks to describe experience as it emerges in some context(s) or . . . as it is lived" (Thompson et al., 1989, p. 135), revealing what people experience and how they experience it (Creswell, 2013). Phenomenological research aims to discover the essential, invariant features of conscious, immediate experiences (Creswell, 2013; Goulding, 2005). Following this tradition, the study posits that a phenomenon has to be understood from the first-person subjective experience and that experiences have to be situated in a context, in the customer's lifeworld (Thompson et al., 1989). Further, it is assumed that theory can be inductively generated based on the phenomenological data, but a researcher's interpretation always involves reflections from theoretical literature (Goulding, 2005; Horrigan-Kelly et al., 2016).

\subsection{Data collection [1]}

To develop a goal-oriented view of customer journeys, the study empirically examines a transformative journey: a journey toward a sober life. It involves a clear higher-order goal and allows the study of customer journeys with different service providers, organizations and products, as well as interactions with various social actors. It also represents an extreme case of a journey toward a higher-order goal, a complex social setting and a long-term process that assists in unveiling the hierarchy of goals and the dynamics therein.

The study was conducted in Brazil over a period of eight months in 2017, employing three complementary data collection methods: observation, phenomenological interviews and a diary method (see Table 2). 


\begin{tabular}{ll}
\hline Method & Contribution of the method \\
\hline Observation & $\begin{array}{l}\text { Creating a pre-understanding } \\
\text { of participants' experiences } \\
\text { and the context of the } \\
\text { journeys (e.g. terminology } \\
\text { and interactions among } \\
\text { members) }\end{array}$
\end{tabular}

Phenomenological interview

Diary method
Gaining an understanding of participants' backgrounds (e.g. what they do, who they live with) and their histories with alcohol; gaining an understanding of the emergence of experiences along the participants' journeys through their retrospective accounts (key events, activities, organizations, social actors and feelings, thoughts and general reactions to these) Deepening the understanding of the journey as a real-time experience; capturing micro events as they happen in the participant's everyday life; detailed descriptions of events
Examples of questions/data

"They talk like the meeting was a way of venting their everyday problems. Some of them talk about how it was when they were drunk. They have the serenity prayer, which is a way of conducting life and they apply it to everyday problems. In sum, my perception is that $\mathrm{AA}$ is not directed at not drinking but the 12 steps involve a completely different way of life" (notes from the meeting on February 13th).

"To start, I would like you to talk a little bit about yourself: who you are, what do you do, your family."

"Do you remember the moment you realized you had a problem?" "Besides going to AA, what else do you do to stay sober?"

"How do you feel after going to church?"

"Can you give me an example of a moment you sought out your sponsor?"

"In this diary, you should describe things related to your recovery process and the search for the goal of sobriety. Here are some examples:
(1) Activities: These activities are related to things you do or stop doing to achieve your goal ...
(2) Events ...
(3) Interactions with other people, companies, organizations ...
(4) Interactions with products or objects ...
(5) Responses and reactions ....”

Volume of data

13 AA meetings seven pages of notes

A goal-oriented view of customer journeys

773
18 interviews 351 pages of text
Ten diaries

between 15 days and two months in length 100 pages of text
Table 2.

Use of data collection methods

Observations contributed to the pre-understanding of the phenomenon and its context (e.g. used terminology) and the confirmation of thematic findings as participants' stories were heard. The first author, a native Brazilian, participated in 13 Alcoholics Anonymous (AA) meetings with three different groups; she listened to participants' stories while observing the settings and interactions among group members and recorded notes on how a meeting worked, what actions were taken during the meeting and how the participants interacted with each other and with their observer. 
JOSM 31,4

For the interviews and diaries, the researcher recruited voluntary participants from the AA meetings. No restrictions were set in relation to personal characteristics or length of sobriety and participants could choose to what extent they wanted to contribute to the study. A small monetary incentive was offered for participation. A total of 18 participants agreed to give interviews and ten of them reported experiences in a diary. Table 3 provides key information about the participants (pseudonyms are used to protect their identities), and its data cover a wide array of experiences and phases along recovery journeys.

For the interviews, a convenient place (e.g. the participant's home or a free AA space) was used. Bevan's (2014) guidelines for phenomenological interviews were followed. To contextualize the phenomenon, the interviewer asked questions about participants' backgrounds and histories with alcohol. To apprehend the phenomenon, the interviewer asked each participant about his/her journey toward sobriety - key events, activities, interactions with organizations and other actors - as well as his/her feelings, thoughts and general reactions to these elements. Finally, to clarify the phenomenological description, the interviewer posed more specific questions related to the experience and its context. Participants gave rich descriptions of their journeys, detailing histories from the moment they started drinking until the moment of the interview.

Diaries offer an effective way of capturing human experiences of everyday life, including experiences as a customer (e.g. Carú and Cova, 2008). To record the diary, written and spoken instructions were given and participants were asked to report anything related to their recovery process without editing their initial descriptions. Three participants used audio recordings and the rest reported their experiences in a notebook. In the diaries, participants described events and problems as they experienced them during everyday life. For example,

\begin{tabular}{|c|c|c|c|c|c|c|}
\hline Participant & Age & $\begin{array}{l}\text { Recovery time, from } \\
\text { last drink or use }\end{array}$ & $\begin{array}{l}\text { Total } \\
\text { recovery time }\end{array}$ & $\begin{array}{c}\text { Length of } \\
\text { interview (min) }\end{array}$ & Diary period & $\begin{array}{l}\text { Member } \\
\text { check }\end{array}$ \\
\hline George & 68 & 37 years & 37 years & 45 & Two months & $\boldsymbol{}$ \\
\hline Larry & 62 & 35 years & 35 years & 89 & - & \\
\hline Steven & 66 & 34 years & 34 years & 64 & Two months & $\boldsymbol{}$ \\
\hline David & 69 & 34 years & 34 years & 67 & - & レ \\
\hline Mark & 59 & 25 years & 26 years & 80 & - & $\boldsymbol{}$ \\
\hline Anthony & 66 & 25 years & 25 years & 146 & Two months & レ \\
\hline Timothy & 53 & 18 years & 20 years & 58 & 20 days & レ \\
\hline Scott & 54 & Two years & 20 years* & 94 & - & \\
\hline Charles & 48 & Five days & 16 years* & 135 & - & \\
\hline Joseph & 65 & One year & 13 years & 51 & Two months & $\nu$ \\
\hline Michael & 43 & 12 years & 13 years & 99 & - & \\
\hline Paul & 27 & Two years & Nine years & 82 & - & \\
\hline James & 44 & Six years & $\begin{array}{l}\text { Eight and a } \\
\text { half years }\end{array}$ & 78 & Two months & レ \\
\hline Jacob & 47 & Two months & $\begin{array}{l}\sim \text { Eight } \\
\text { years* }\end{array}$ & 53 & 15 days & \\
\hline Robert & 38 & Five years & $\begin{array}{l}\text { Five and a } \\
\text { half years }\end{array}$ & 72 & - & レ \\
\hline Thomas & 65 & 2.3 years & $\begin{array}{l}\text { Three and a } \\
\text { half years }\end{array}$ & 104 & Two months & $レ$ \\
\hline John & 40 & One and a half years & $\begin{array}{l}\text { One and a half } \\
\text { years }\end{array}$ & 79 & $\begin{array}{l}\text { One and a } \\
\text { half months }\end{array}$ & $レ$ \\
\hline Frank & 56 & One year & One year & 90 & $\begin{array}{l}\text { One and a } \\
\text { half months }\end{array}$ & \\
\hline
\end{tabular}

Table 3.

Note(s): * multiple relapses 
someone might state in their interview that anger is "a poison for alcoholics"; in the diaries, they would describe events that made them angry, thoughts about relapse and what they did to overcome the situation.

\subsection{Data analysis}

Systematic procedures grounded in interpretive phenomenology and the idea of a hermeneutic circle were followed during the data analysis. The analysis advanced in two stages following the iterative process of interpretation between parts of the textual material and the whole, first for the individual stories and then for the whole set of stories (Thompson et al., 1989). In the first stage, the researcher read all available material for each participant as a whole. Significant statements in vivo were then coded and noted in a separate notebook. Emerging themes related to (1) the nature of the customer experience, (2) the interactions with other actors and (3) the elements of an overall consumer journey toward sober life were subsequently identified and described.

In the second stage, a new part-to-whole procedure was completed. The researcher reviewed all the theme notes related to individual stories in order to gain a comprehensive understanding of the data. Themes were integrated based on their similarities, identifying global patterns in the data (i.e. the essential features or general structure of the phenomenon). The textual material was then revisited to corroborate the interpretation and member checks were conducted to ascertain that it was acceptable and meaningful to the participants. Following the ideals of interpretative phenomenological research (Horrigan-Kelly et al., 2016; Thompson et al., 1989), primacy was given to subjective experience over prior research knowledge and an emic (rather than an etic) approach was used to label the phenomenological categories presented in the results. The role of the literature only became visible in a later stage.

\section{Findings of the empirical study}

The phenomenological analysis resulted in the identification of three iterative processes that described the recovering alcoholics' journeys toward a sober life: (1) recognizing the problem and setting the goals, (2) changing habits and behaviors and (3) overcoming obstacles and temptations. The following subsections describe the nature of a transformative journey and its associated experiences, structured according to these key processes.

\subsection{Recognizing the problem and setting the goals}

Our findings indicate that, for the recovering alcoholic, recognizing and accepting the problem and setting goals are dynamic and ongoing processes, making it difficult to pinpoint when such a journey begins. The study participants' stories revealed that the goal evolved from reducing alcohol consumption to stopping consumption to changing one's life or becoming a new person. Many participants described starting this process by admitting that they were drinking too much and recognizing the need to reduce consumption, often prompted by family members and friends who pointed out the problems the alcohol was causing. Recognizing and accepting the problem appeared to be an iterative process characterized by many new beginnings and a gradually broadening goal:

When it was dawn, I would promise myself, "So, today, until noon, I will not drink," and sometimes I did not, but then from the afternoon to the night, I used to consume the quantity that I did not consume in the previous day, or even more (Thomas, interview).

After realizing they were unable to reduce consumption, their goal evolved to stopping drinking altogether. Some of the participants explained that their initial goal was to stop drinking for a while until their problems were reduced or until they had disappeared. However, as they proceeded on their journey, they accepted that they had a disease and could

\section{A goal-oriented view of customer journeys}


JOSM 31,4

not consume even a sip of alcohol. One informant explained the difference between recognizing and accepting one's problem:

While the person does not accept that he is sick, he remains reluctant. While he can work here or there, he keeps working and drinking, drinking and working; he keeps slacking. It's only when he is losing everything or almost everything that he gives up. "No, wait, I am sick." . ... Then, I accepted; before, I only used to admit, "Wait, I admit that I am drinking too much; I admit that I need to stop for a while, give it a break." ... . Then things eased for me, and my suffering also softened, "I am sick." Then I went to the meeting. . . (George, interview).

It was common for the participants to accept their addictions after enduring an extremely negative experience (what recovering alcoholics call reaching rock bottom), when they received a "spiritual awakening." For instance, Charles' first real decision to stop drinking came after he and his friends got drunk and had a car accident in which his best friend died. For Robert and Anthony, the decision came after they heard their doctors talking about their risk of dying, which made them extremely fearful. Timothy talks about hitting rock bottom:

Then I got into a physical fight with this person and entered my father-in-law's house. Then he hit me in the head with a wood stick. ... Then I passed out and went to the hospital. Then in the hospital ... 28 stitches. I stayed alone there. .... "Oh, now everything is lost.” .... I felt like human waste. From the hospital, I was admitted to a clinic (Timothy, interview).

Many of the participants explained that their goal evolved from stopping drinking to becoming a sober person, which involved making changes beyond abstinence. The goal became something bigger: a change of life and becoming a new man. As Larry explained:

The key is not only stopping drinking; it is the real change of character..... Because if there is not a change of character, one will continue drinking, simple as that. Stopping [drinking] is easy .... To stay stopped, there needs to be a change of character..... There is a key expression that says. ..: "the man that I was drank, and the man that I was will drink" (Larry).

This goal is often supported by seeking help from clinics, treatment centers or AA, where alcoholics learn that abstinence will not last if they remain whom they were, behaving as they had when drinking. Participants who underwent detoxification often relapsed if this continuation of treatment (through the 12-step program) was missing or if they thought they were cured and could continue drinking. Many participants described how these programs made them face their problems and identify behaviors that needed to be changed. For instance, the 12-step program recommends that recovering alcoholics amend their past mistakes by asking forgiveness from people they hurt when drinking. This was described as a distressing but necessary experience for those wanting to stay sober. Paul described how having his defects of character yelled to his face helped him accept his problem:

And after the third month [of treatment on the farm], we go through the confrontation, where the older guys of the ... farm ... can see your defects of character. .... It is very tense because it ... shakes your feelings very much. .... We were 51 [people], so we sat in a circle, from the oldest to the newest, and then it goes, and one sits in front of you, eye-to-eye, opens their arms and [yells]: "You'rea bum, ... you do not read, you do not seek [help], you stole from your family, you're arrogant!" .... Then your mask falls ..., and it was a shock to me, I cried and everything, but I got a shock of reality and started facing [my problems] (Paul).

During recovery, the goal evolved to maintain sobriety as the desire to drink was reduced or removed. To attain the new goal, recovering alcoholics still needed to become the new person they wanted to be while being aware of their defects of character, behaviors, traps and temptations. In the participants' words, they had to "stay alert." Recovering alcoholics keep going to AA meetings, which they call daily maintenance, so that they can keep convincing themselves that they are alcoholics: 
Being convinced that we are alcoholics is also progressive. It does not happen overnight. . ... I, for instance, am not hit by doubt because I have regular attendance at the meetings, but I cannot guarantee you that, if I interrupted this regular attendance at the meetings, this conviction that I have a problem with alcohol would start to fade. I saw it happen countless times (Larry).

\subsection{Changing habits and behaviors}

The participants highlighted that setting goals prompted them to change their habits and behaviors to stay sober. Some of the necessary changes related to abandoning existing behaviors, where the key change obviously related to stop drinking. Many participants attended clinics and hospitals for detoxification, and they sought help from the AA and selfhelp groups, where they would typically receive medical treatment and counseling. The participants described detoxification from alcohol caused extremely negative experiences such as shaking, sweating, pain, nervousness and anxiety. However, these experiences derived from a lack of alcohol had a tendency to weaken and vanish over time. Beyond giving up drinking, the participants explained that they also needed to abandon habits that were associated with alcohol: they could no longer go to bars, engage in activities associated with alcohol such as games and dances or consume products that might contain or be associated with alcohol. The participants stated that they tried to keep the disease quiet.

This monster that is alcoholism is asleep inside me and I cannot wake it up. And what awakens a monster inside me? . ... It is the smell of alcohol. I cannot even put aftershave lotion with the smell of alcohol. .... I [also] do not mix in my food alcohol vinegar (Anthony, interview).

The participants also described taking on new behaviors that supported sobriety, for example, attending AA meetings and church. Going to church and praying were new habits that gave recovering alcoholics the strength to face obstacles, helping them deal with negative emotions and feelings while overcoming defects of character and imperfections. Some participants described the relief they felt when sharing their stories and how they experienced insightful moments when listening to other recovering alcoholics' stories at AA meetings:

Our medicine is the attendance to the meetings; it is in the listening and talking. This is our medicine, what enters through the ear and leaves through the mouth (George, interview).

Many participants noted that filling their time with new activities, even those unrelated to sobriety, was very important in their journeys. According to Anthony, idleness is the recovering alcoholic's enemy. New habits and activities were described as therapeutic, anxiety-reducing and pleasurable. For Michael, meditation made him feel pure. For Timothy, making crafts at home reduced hyperactivity. Joseph, who practices gardening, and Larry, who practices physical activities, detailed the importance of filling their idle time:

Every weed I remove is like a cup of alcohol that I do not drink (Joseph, diary).

This idle time that was spent in the bar-and it was a considerate amount of time, about 4 or $5 \mathrm{~h}$ a day... - started to be vacant. And I was 29 years old, stopping drinking ..., there was energy left. I went biking, swimming .... One, because I had to fill the time, and two, because anxiety came in, and the physical activity removed anxiety. I would pedal $50 \mathrm{~km}$ and would come back calm (Larry).

Just as recovering alcoholics replaced habits and activities, they also needed to replace people in their lives; they needed to avoid old friends who drank because those friends would insistently invite them to drink, something commonly described by the participants. Self-help groups offered opportunities to socialize with peers undergoing the same journey. Recovering alcoholics believed it was important to interact with people on the same path because they could show the way to a sober life: 
JOSM 31,4

If it was that agony from the first days ... it is humanly impossible to support. So, there it comes, one of the advantages of the group is this: the mates are there during those first days to say, "It is going to pass. It is going to pass" ..., and that one who is starting [the journey] has to have faith .... A doctor can advise, "Look, it is going to pass," but there will be always that argument: "But that did not happen to you, you did not go through this" (Larry).

Other recovering alcoholics then became friends, "second family," or "brothers." They offered social activities outside the group and enjoyable meetings and conversations not necessarily related to their disease. In short, they replaced the social relationships they used to have, helping them avoid "old friends," which is fundamental to recovery considering that, for many of the recovering alcoholics, there were no friendships beyond their circle of "drinking buddies." Anthony's words exemplify the social aspect of interacting with other AA members:

The first [important event] was in the afternoon when I went to the [AA] office to receive the mate returning to be on duty .... There I found, beyond the pertinent service, [mates having chimarrão (local tea)] with peanut butter. It looked like a child's birthday party: four grown men eating candy and chatting..... For me, that was a recovery meeting. Duty ends at 5 p.m. [Then] we realized it was $5: 40$ p.m. .... No doubt that being together with mates is what keeps us sober (Anthony, diary).

The informants also describe a range of behaviors related to changing their lives and becoming new men. These include no longer deceiving people and not being egocentric, for example. For Paul not being egocentric translates on a more concrete level into not playing music, while for John not deceiving people translates into returning money to someone who lost it, something he would not have done in the past:

Why [did I stop doing] music? Because it is going to inflate my ego. . ... It hurts. I feel sad. . . . I'm a poet, and my poetry comes naturally, sometimes inspiration comes. The other day, I was alone at home and inspiration came. I started writing something and left it on the table. My girlfriend asked, "Are you going to start with this again?" ... That gave me a bad feeling, you know, "Dude, I cannot write," you know?! I felt like arguing with her, but instead I took the sheet [with the music] and threw it away, in pain (Paul).

On Saturday, I came across a situation here in my workplace, where I found an amount of money inside a car..... A proof of change, it is to deliver to the owner ... knowing that it does not belong to me, right? It is a thing that I do, and it makes me joyful: the habit of change (John, diary).

The positive experiences derived from changing habits and behaviors enhance the recovering alcoholics' commitment to the goal and keep them motivated to continue their journey, such as when John feels joy when he does the right thing. However, this journey is also marked by the negative experiences derived from the adoption of new behaviors and habits (e.g. asking someone for forgiveness is distressing) as well as the abandonment of behaviors, habits and people (e.g. the side effects of abstinence from alcohol). However, sometimes these negative experiences also increase recovering alcoholics' commitment to their goals, such as how having his defects of character yelled in his face helped Paul face his problems.

Finally, replacing behaviors and social connections characterize the beginning of the recovering alcoholics' journey. As they continue, the new behaviors they adopt become habits that help them maintain their path toward a sober life. As seen in section 4.1, their goal evolves to maintain a sober life when they do not feel the desire to drink anymore. Nonetheless, the participants believe that, if they abandon these habits and behaviors they acquired at the beginning of their journey, relapse becomes a threat.

\subsection{Overcoming obstacles and temptations}

The third key process evident in the data relates to overcoming obstacles and temptations to avoid slipping in the journey toward recovery. Some temptations can be avoided by changing habits and behaviors, yet many triggers emerge in everyday life. The 
respondents described that their desire to drink could emerge when viewing a television advertisement with an ice-cold beer, having a dream about drinking or even when cooking a particular dish. Scott describes an episode where he could taste alcohol by accidently smelling it:

I had entered AA 30 days earlier .... I sat on the seashore, beside a kiosk, and in that kiosk, they were preparing caipira [a traditional Brazilian cocktail] .... And that big cachaça smell came .... The feeling I had was that I was drinking, that that cachaça was going down my throat. I feel its taste. I have to get away $(\mathrm{Scott})$.

The participants described several ways of overcoming obstacles and temptations that they learned from AA meetings, literature, sponsors and other recovering alcoholics. The AA offers them the most important trick for staying sober: "Avoid the first sip every $24 \mathrm{~h}$." This reminds them that abstinence is possible. Many informants explained that, to overcome the desire to drink, they can substitute the drinking with other things, such as eating candy or drinking coffee. Support from friends or fellow AA members also plays an important role in overcoming temptation.

I had stopped for less than three months. I was in a neighbor's apartment, and he had gone out, and I was talking to his wife. .... Then, he entered the apartment, he arrived with wine and opened that big bottle of wine, and I was not prepared. And I smelled that wine, and that disturbed me. For three days, I had the desire to drink .... I used to use the trick of having soda and eating candy, and going to the groups to have coffee, have chimarrão, talk. During those three days, nothing worked. The desire did not go away, but [the AA members] told me, "No, desire comes and goes" (Mark).

Obstacles for maintaining a sober life and the temptation to relapse can also emerge indirectly through negative life experiences. When recovering alcoholics face problems in their everyday lives, negative experiences such as anger, irritation or sadness function as triggers that activate the desire to drink. For example, Charles described that he relapsed when things went wrong in his marriage or professional life and caused him extreme negative experiences. Scott shares the idea that these negative feelings are a significant obstacle for maintaining sobriety:

Resentment ... to us it is a poison. .... Resentment and anger inside an alcoholic, at least with me, annihilates me. I cannot feed this (Scott).

Participants described that they learned how to deal with their negative experiences in AA, whether in meetings or in the literature. For example, Thomas says that he learned how to react to conflicts and problems in AA. For Joseph, AA taught him how to have patience:

I went in the morning to schedule an appointment [with an ophthalmologist] and then he scheduled another for the afternoon. I went in the afternoon and he rescheduled to the next Wednesday afternoon. If I were active [drinking], I would have thrown everything in the air and gone to have my cachaça. But now, AA has taught me to have patience (Joseph, diary).

When these negative life experiences appear, recovering alcoholics can apply the learned tools (e.g. reading reflections, talking to mates, doing the serenity prayer or going to meetings) or they can do something that helps them distract their minds. Anthony and Joseph reported in their diaries what they do when they "lack serenity" or think about a relapse:

Every time I lack serenity, I run to the group, which is $200 \mathrm{~m}$ away from my house. Because I have the key, I make the group my safe haven; I believe there is a spiritual aura or something blessed by the Superior Power in this space (Anthony, diary).

I woke up somewhat thoughtful. .... I even thought about a relapse, but I came to the conclusion that it would not be any good to fall back at this point. I went down to my flowerbeds to take care of my vegetables, and I calmed down. My thoughts went elsewhere, and I thought that if I had drunk, I would be lost (Joseph, diary). 
JOSM 31,4

780
Some informants explained that another way of overcoming obstacles and temptations is to compare their current life to their drinking life, thinking about everything they sacrificed to stop drinking and what they would lose if they drank again. Undergoing a negative experience makes the recovering alcoholic compare himself to others or to his "old-self," thus rationalizing and reducing this negative experience to a neutral state. All participants reported the benefits of a sober life: they were happier with their new family life, they felt healthier and more disposed to physical activities, they had new relationships and less desire to drink. These positive experiences, derived from staying sober, motivated them to overcome temptations.

\section{Interpreting the journey toward a sober life with the self-regulation model of behavior}

The phenomenological findings regarding the recovering alcoholics' journey toward a sober life were interpreted using the self-regulation model of behavior (Carver and Scheier, 1998). The model is useful to analyze goal-oriented journeys as it shifts the emphasis from the purchase process to understanding the processes through which consumers pursue higher-order goals. It also helps make sense of the evolution as well as the hierarchy of goals evident in the recovering alcoholics' behavior and the role that experiences play in the process. Figure 2 presents an abstracted framework of the consumer's cognitive and behavioral processes that describe how consumers set goals and seek to change or maintain their experienced situations with regard to their goal. These processes are repeated in an iterative fashion throughout the journey toward the goal.

\subsection{Setting goals}

In the phenomenological study, recognizing the problem and setting the goal was identified as a key process in the recovering alcoholics' journey. In the abstracted framework, this is labeled as "Setting goals," referring to the consumer's iterative cognitive processes of identifying the higher-order goal, relevant subordinate goals and revising these goals throughout the journey. According to the self-regulation model, the consumer's goal is the reference value against which the consumer evaluates his/her situation and seeks to adjust his/her behavior accordingly. In

Figure 2.

Iterative cognitive and behavioral processes along a goal-oriented customer journey

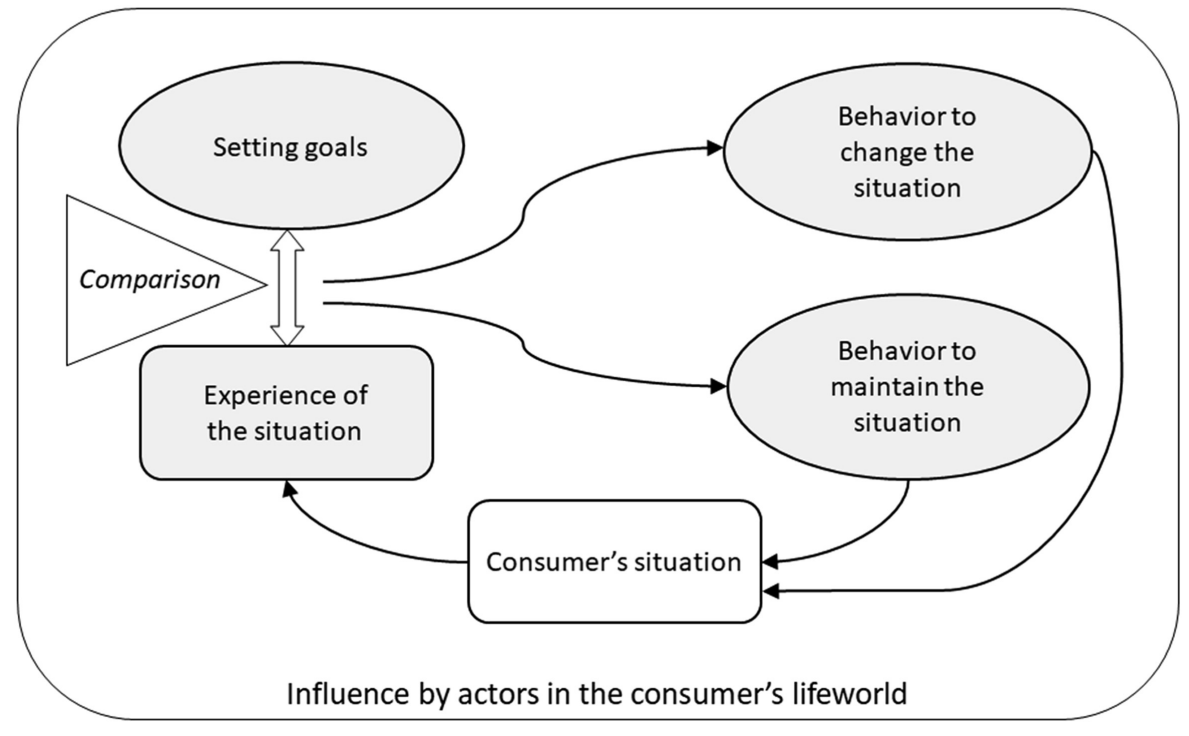


the model, the output of feedback loops operating at higher levels of the hierarchy provides the goals for those feedback loops operating at lower levels (Carver and Scheier, 1998; Powers, 1973). In a similar vein, pursuing a sober life as a higher-order, superordinate goal subsumes the subordinate goals necessary for its attainment. This also implies that the iterative process presented in Figure 2 happens at multiple levels of goal abstraction.

In the findings, the higher-order goal evolved from reducing drinking to living a sober life. Recovering alcoholics identify the subordinate goals necessary for this to happen, such as changing their habits, working on their defects of character, building new social contacts and learning tricks to overcome temptations. For each of these goals, they identify further subordinate goals. For example, to live a sober life (higher-order goal), recovering alcoholics need to get rid of defects of character (subordinate goal). To rid themselves of defects of character (higher-order goal), recovering alcoholics adopt several new reference values prescribed by the 12 steps of AA (subordinate goals).

Goals at lower levels can be seen as a means to achieve goals at higher levels (Carver and Scheier, 1998). Hence, consumers continuously set subordinate goals that help them achieve their higher-order goals. Therefore, while all recovering alcoholics share the same higherorder goal (living a sober life), the subordinate goals can differ between them. While some recovering alcoholics cannot have alcohol at their house, others are not tempted by it. In the same vein, consumers can set new subordinate goals when they realize that the ones guiding them in the moment are not reducing the discrepancy between their current situation and their higher-order goal. The goals then continuously evolve until effective goals that reduce the discrepancy between the current situation and the higher-order goal are set. For example, in the empirical study, a few participants thought they were able to go to bars in the beginning of their recovery but, as they proceeded in their journey, they set a new goal of staying away from bars because they realized they needed to do so to live a sober life.

\subsection{Experiences as a means of perceiving a consumer's situation}

The self-regulation model of behavior describes that individuals compare their goals with their perception about the current situation (the input function) (Carver and Scheier, 1982, 1998). The findings indicate that experiences play an important role in the formation of this perception. For recovering alcoholics, the desired situation is feeling free of temptations and other negative experiences that might trigger them. The findings indicate how consumers often use sensorial (e.g. the desire to drink) and emotional experiences (e.g. anger and sadness) to create a perception about their current situation (i.e. input), which then spurs behavior, such as going to an AA meeting.

Experiences can therefore be considered as drivers of behavior in goal-oriented journeys. Recovering alcoholics can adjust their behavior when there is a discrepancy between their current experiences and goals or they can maintain their behavior when they do not perceive this discrepancy. It follows that negative experiences can be beneficial when considering the attainment of a higher-order goal as they signal the need to change or maintain behavior.

\subsection{Behavioral processes to change or maintain experienced situations}

This study describes how recovering alcoholics seek to change their habits and behaviors in order to pursue their goal of a sober life and how they try to overcome obstacles and temptations to avoid slipping from their path. According to the self-regulation model, the consumer adjusts his/her behavior (the output function) to minimize a discrepancy between his/her perception about the current situation and his/her goal. As recovering alcoholics use experiences to form a perception about their current situation, when they feel a discrepancy between their experiences and their goals, they try to adjust their behavior to reduce it. The adjustment affects the consumer's situation, which leads to a new experienced situation. 
JOSM 31,4

782

In the phenomenological findings, changing habits and behaviors appeared to be significant in the early stages of recovery: when recovering alcoholics feel the desire to drink, they have to replace earlier behaviors and get rid of habits to reduce this temptation, such as giving up games, bars and friends. The empirical findings demonstrate that obstacles and temptations may emerge throughout their journey, such as when recovering alcoholics accidently smell alcohol. Such external factors can emerge at any point and change the perceived present situation (Carver and Scheier, 1982, 1998). In these cases, recovering alcoholics engage in behaviors to overcome obstacles and temptations, such as praying, going to a meeting or calling their sponsor. These behaviors then mitigate the negative experiences, shifting recovering alcoholics' perceptions about their situation closer to the goal.

Not all behaviors in the recovery journey are directed at changing the experienced situation. Once consumers achieve a desired situation in their journey and no longer feel an overwhelming desire to drink (i.e. there is not a significant discrepancy between their experiences and goals), they engage in behaviors directed at maintaining this experiential state. The feedback loop functions as a process of keeping the goal by keeping the experienced situation close to the goal (Carver and Scheier, 1982; Powers, 1973). In the data herein, this was illustrated by recovering alcoholics who were sober for many years and remained engaged in certain behaviors (e.g. going to meetings), while remained disengaged from others (e.g. continuing to avoid bars), so that the desire to drink did not return.

\subsection{The influence of other actors}

The study also demonstrates how a range of actors can influence the recovering alcoholics' processes in pursuit of their goals. Family and friends as well as the AA organization and its members play a crucial role in helping recovering alcoholics set their goals. The AA, for instance, through the 12-step program, offers several standards for behavior that affect the alcoholic's goal setting. Other recovering alcoholics are also trusted to help in identifying these goals as they know the path to living a sober life.

The self-regulation model recognizes that external and social influences can affect the situation against which the consumer compares his/her goal (Carver and Scheier, 1990). The findings also demonstrate that other actors can influence the recovering alcoholics' experiences positively or negatively. When old friends make fun of recovering alcoholics for going to AA or when they drink in front of them or offer them drinks, the experiences can be negative, causing negative sensations, emotions and thoughts. Alternately, other actors can influence recovering alcoholics' experiences positively, for example, by praising their recovery and having normal conversations with them.

The behaviors consumers engage in throughout their journeys can involve interactions with market, organizational and/or social actors. Individual behaviors are those that consumers perform utilizing only their own means, but they typically need complementary resources from external actors to bring their experienced situations close to their goals. For instance, recovering alcoholics may engage in customer journeys with market (e.g. healthcare service providers) or organizational actors (e.g. self-help groups) in which other social actors (e.g. recovering alcoholics, friends and relatives) also play an important role. Therefore, the consumers' behavioral processes in pursuit of their goal involve engaging in various touchpoints with market and organizational actors in which consumers aim to approximate their experienced situations to their goals. These findings highlight the embeddedness of touchpoints and customer journeys in consumer journeys toward higher-order goals.

\section{A goal-oriented view of customer journeys}

The interpretation of the phenomenological findings with the self-regulation model of behavior provides a new understanding of customer journeys. This section answers the 
research questions concerning the structure of the goal-oriented journey, its processes and the role of the customer experience (Figure 3).

\subsection{The structure of the goal-oriented customer journey}

Aligned with the self-regulation model of behavior (Carver and Scheier, 1982, 1998) and the phenomenological findings, this study portrays journeys as goal-oriented and hierarchical. Assuming that goals are organized in hierarchies with superordinate and subordinate goals (Carver and Scheier, 1982, 1998; Powers, 1973), the goal-oriented customer journey depicts multiple levels of journeys directed at different levels of goal abstraction. Aligning this idea with previous research on the customer experience and journeys, this study proposes three key levels: the consumer journey, the customer journey and touchpoints (cf. Hamilton and Price, 2019), as illustrated in Figure 3.

The consumer journey represents the journey consumers engage in when pursuing higher-order goals (Hamilton and Price, 2019) and includes multiple customer journeys, interactions with market, organizational and social actors and consumers' individual behaviors. The consumer journey therefore represents a superordinate journey to the customer journey level, which, according to Patrício et al. (2011), is the level the customer experience literature typically focuses on. For recovering alcoholics, the consumer journey is the journey toward a sober life, and it involves taking on customer journeys with health-care centers, AA, medications and self-help books while disengaging from customer journeys with bars or products that trigger their temptation to drink. Hence, a consumer journey encompasses many complementary customer journeys.

Customer journeys represent the journeys consumers engage in with market and organizational actors in pursuit of subordinate goals. The customer journey is subordinate to, and embedded in, the consumer journey. A single customer journey may help a consumer achieve one or multiple subordinate goals but it is insufficient to achieve a higher-order goal. The customer journey with AA, for instance, involves all interactions recovering alcoholics have with the organization, including meetings, events and literature. Such a customer journey helps recovering alcoholics achieve several subordinate goals that work in function of living a sober life, such as staying away from bars, overcoming temptations and learning how to stay sober. Interestingly, the AA also offers services for other actors (i.e. social touchpoints) in the consumer's environment that might influence recovering alcoholics' experiences (e.g. meetings for relatives to learn how to deal with the recovering alcoholic).

Each customer journey consists of multiple touchpoints (Lemon and Verhoef, 2016; Patrício et al., 2011) that focus on goals further down the level of abstraction (e.g. getting a specific task done). Touchpoints refer to the episodes where a consumer directly or indirectly "touches," contacts or interacts with a market or organizational actor to achieve a concrete goal (cf. Zomerdijk and Voss, 2010). Interactions in a specific touchpoint are embedded in the customer and consumer journeys. In the findings, touchpoints refer, for example, to specific moments where recovering alcoholics interact with AA through meetings, literature and WhatsApp groups to achieve an immediate goal.

It is important to note that these processes happen simultaneously at all levels. Therefore, if a consumer is interacting with a particular touchpoint to achieve a concrete goal, this consumer is simultaneously engaged in a consumer journey to achieve a higher-order goal.

\subsection{Processes within the goal-oriented customer journey}

This study identified cognitive and behavioral processes that relate to how consumers set goals and seek to change or maintain their experienced situations regarding their goal (Figure 2). In other words, consumers set the higher-order and subordinate goals at different levels of abstraction, compare their situations - sensed through affective, cognitive, sensorial, social and physical experiences - with these goals (cognitive processes) and act to change or
A goal-oriented view of customer journeys 
JOSM

31,4

784

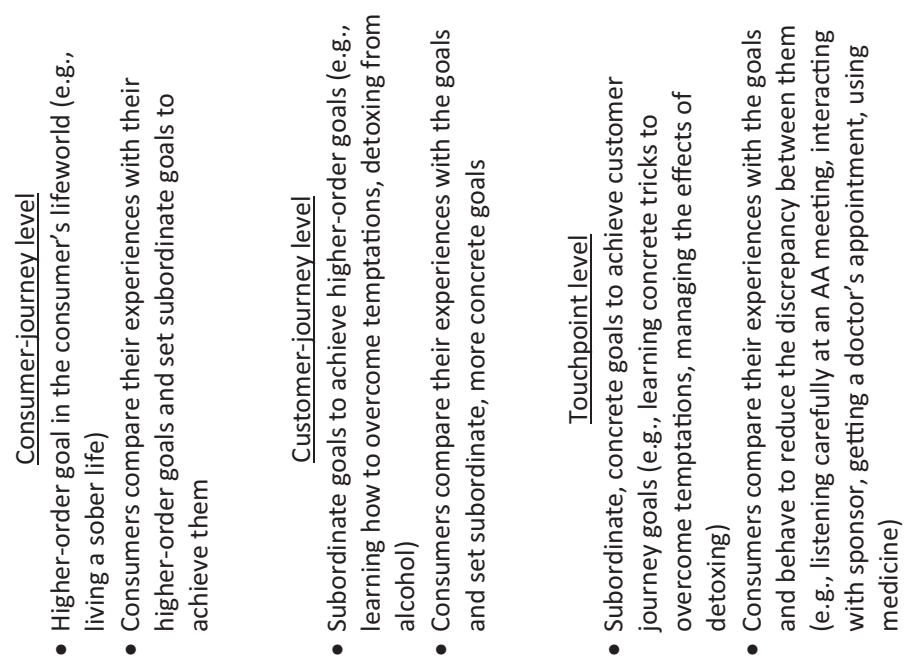

Figure 3.

Theframework for the goal-oriented customer journey

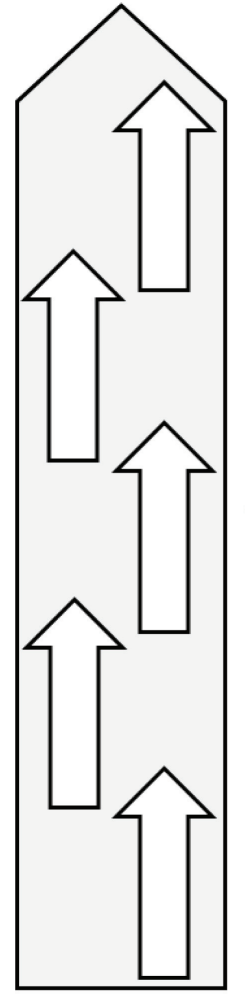

Consumer journey

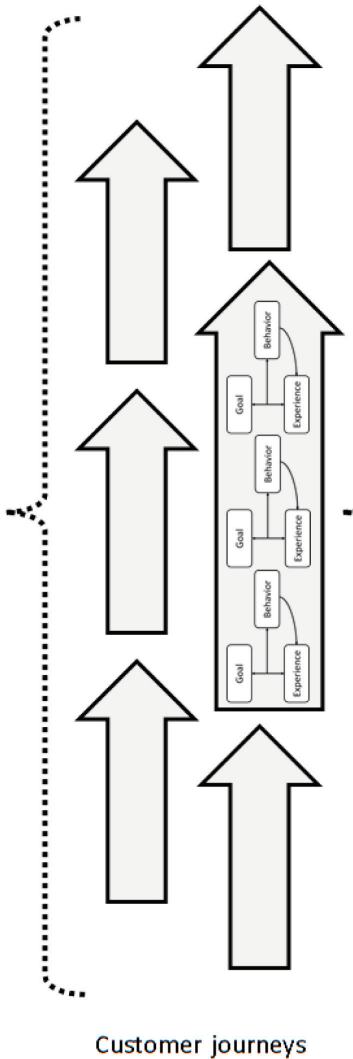

Customer journeys

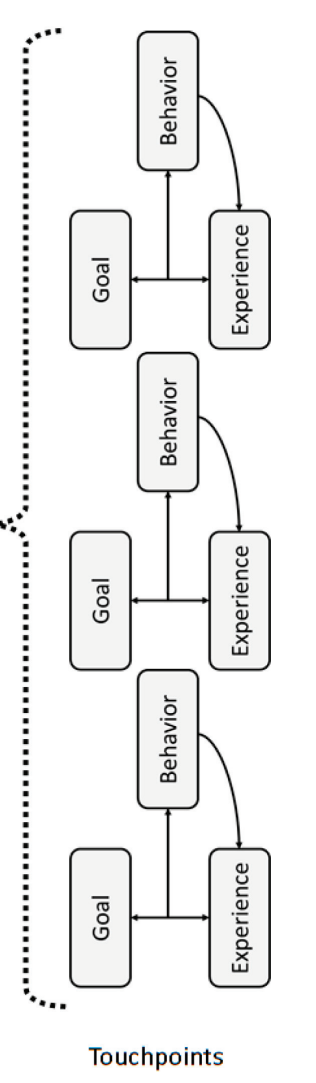


maintain these experienced situations (behavioral processes), as represented by the iterative process within the journeys in Figure 3 . Consumers are thereby constantly trying to reduce the discrepancy between their experienced situations and their goals.

As the goal-oriented customer journey presents a hierarchical structure and consumers set several subordinate goals, consumers manifest this iterative process for each goal. For example, to live a sober life (higher-order goal), Paul compares his experienced situations with this goal. As the output at this level, Paul sets subordinate, more concrete goals that help reaching this higher-order goal, such as working on his ego (subordinate goal). Consumers repeat these processes of comparing their experienced situations with their goals and setting subordinate goals at several levels until concrete goals are established and then engage in behavioral processes to maintain or adjust their situations vis-à-vis the goal.For example,Paulmanages his ego by going to AA, reading and no longer writing music. Therefore, while the cognitive processes of comparing experienced situations with goals happen at all levels (consumer and customer journeys and touchpoints), the behavioral processes involved in a consumer journey happen at the touchpoint level.

\subsection{The role of the customer experience during the goal-oriented customer journey}

This study indicates that experiences can contribute to consumer goal attainment by serving as an input to the process of comparing a consumer's present situation and goal, which ultimately directs consumer behavior (cf. Carver and Scheier, 1982, 1998). Creating the input (i.e. perceiving the current situation) is a complex process that involves various sources of information (Carver and Scheier, 1998). The results indicate how the customer experience functions as a source of information about the consumer's situation and how the consumer then compares the experienced situation with his/her goals before engaging in subsequent behavior. Therefore, experiences not only emerge as responses to stimuli but also drive behavior toward the goals.

Negative experiences can thus play a positive role in reaching consumer goals within goal-oriented customer journeys and may contribute to positive experiences at higher levels of the journey. This happens, for example, when a recovering alcoholic uses endured pain as motivation to remain sober. In other cases, however, negative experiences are just unavoidable consequences of necessary discrepancy-reducing behaviors, such as the physical pain felt after going to the gym for the first time. In these cases, negative experiences do not contribute to the consumer's goal per se but the stimulus that triggers those experiences does. Hence, maximizing the positive customer experience might not be the consumer's priority, at least in the case of transformative consumer journeys. This study also shows that negative experiences may play an important role in the process of setting or adjusting the goals.

Viewing journeys from multiple analytical levels allows for analysis of the emergence of experiences at multiple levels as well. Experiences emerge as responses and reactions to specific stimuli in lower journey levels (e.g. touchpoints) but consumers can also describe overall experiences that emerge in a customer or consumer journey. The literature on customer experience suggests that the experiences at lower levels combine to form dynamic experiences that evolve over time at higher levels (Kranzbühler et al., 2018), although it is not clear how this higher-level formation occurs. The results indicate that experiences emerging at lower journey levels do not necessarily have a cumulative effect on experiences described at higher levels (i.e. negative experiences do not necessarily detract from an overall positive experience) but it depends on how the experience contributes to the consumer goal. Figure 3 illustrates the main findings.

\section{Conclusions}

\subsection{Theoretical contributions}

This study develops a goal-oriented view of customer journeys that is customer-centric and describes consumers' cognitive and behavioral processes and the role of experience in 
JOSM 31,4

786

relation to their goal. This study highlights the importance of looking at the consumers' higher-order goals to obtain a goal-oriented view of the customer journey. Such an approach answers the recent calls for a more holistic view of the customer experience (Kranzbühler et al., 2018), revealing theoretical insights into the structure of customer journeys, their processes and the role of experience.

This study contributes to the customer experience literature by depicting the customer journey as goal-oriented and hierarchical, extending the ideas proposed by Hamilton and Price (2019). A few studies have conceptualized the customer journey as goal-oriented (e.g. Halvorsrud et al., 2016) but they have focused on the customer's immediate, concrete goals. By considering the consumer's hierarchy of goals, this study highlights the embeddedness of touchpoints and customer journeys into the broader goal-oriented consumer journey. This is important to avoid a myopic view that focuses on immediate, lower-order goals and creates a risk of losing sight of obvious opportunities to improve customer experience.

This study presents three key levels of the customer journey - the consumer journey, the customer journey and touchpoints - attending calls for research about its multilevel structure (Patrício et al., 2011). The conceptualization of the consumer journey as a superordinate level of the customer journey contributes to the current knowledge geared toward the level of customer journeys, firms and offerings. Understanding the consumer journey toward higherorder goals helps in the development of a broader, more customer-centric understanding of the customer journey that views customer experience as embedded into the customer's lifeworld (cf. Akaka and Vargo, 2015). It is important to highlight that the consumer journey differs from related concepts such as the customer's value constellation (Patrício et al., 2011), the service delivery network (Tax et al., 2013) and the experience domain (Baron and Harris, 2010) because these concepts tend to focus on the network of actors who contribute to an overall and connected service (Tax et al., 2013) or activity, such as entertainment (Patrício et al., 2011). The consumer journey focuses on a consumer's processes toward a higher-order goal and likely involves several distinct services and activities. The goal-oriented view hence complements existing customer-centric approaches by offering a novel view that can facilitate understanding of customer value creation in their lifeworld (cf. Heinonen and Strandvik, 2015).

This paper also describes the iterative cognitive and behavioral processes that relate to how consumers set goals and seek to change or maintain their experienced situation with regard to their goal. Existing customer experience literature has provided insight into specific consumer behaviors and activities related to a service or overall activity (e.g. recognizing a need and searching for information) (e.g. Lemon and Verhoef, 2016; Patrício et al., 2011). This study identifies more general processes underlying customer journeys anchored on consumers' goals. This perspective has remained missing in extant literature.

The study also describes the important role of the customer experience on the goaloriented customer journey. With the self-regulation model of behavior, this study proposes a closed loop system as an alternative approach to the role of the customer experience, viewing it not only as responses to stimuli but also as a driver of behavior (cf. Powers, 1973). Although the customer experience literature recognizes that previous experiences influence future expectations (e.g. Lemon and Verhoef, 2016), most studies have restricted their view to the outcomes that customer experiences have for the firm, such as customer brand perceptions or customer loyalty (e.g. Brakus et al., 2009), giving less consideration to how experiences can influence the course of the journey.

By considering the customer experience as a behavioral driver, this study also finds that negative experiences can contribute to a positive overall experience that emerges in the process of pursuing a higher-order goal, something that the literature has not addressed so far. Therefore, calculating averages for individual experiences at touchpoints is misleading as a measure of overall experience; the emergence of experience is a complex and dynamic 
process. The results indicate that experience does not emerge in a cumulative manner but the impact of individual experiences depends on their contribution to the consumer's goals. These findings contribute to the customer experience research study that has tended to measure customer experience either in one touchpoint or as an aggregate evaluation of the brand, as shown in a recent review by Becker and Jaakkola (2020).

\subsection{Practical implications}

Focusing on the consumers' higher-order goals and obtaining a holistic picture of the journey toward them highlight many opportunities for firms and organizations to help consumers achieve their goals. Firms and organizations should strive to understand and map the customer journey on all levels, including the consumer journey. Mapping the consumer journey goes beyond identifying touchpoints in a customer journey; it involves identifying multiple customer journeys and consumer behaviors that are part of the consumer's highergoal pursuit. In addition, it involves understanding how distinct customer journeys relate to each other. As there are several ways to achieve a higher-order goal (Carver and Scheier, 1982), it is important that firms and organizations consider how their offerings fit in the broader configuration of journeys undertaken by consumers. For example, it would have been helpful for clinics to identify customer journeys with self-help groups as complementary and sequential to detoxification, facilitating the transition to them.

After obtaining this holistic map, firms and organizations can act to influence the customer experience and help customers keep it close to their goals. As consumers proceed in their journeys by trying to approximate their experiences to their goals, firms and organizations can offer resources that help consumers in this process and collaborate with other actors that offer complementary resources. Additionally, firms and organizations can extend their services to social actors that interfere in the consumer's experiences. The AA, for example, recognizes the role of families in the recovery journey, so it offers Al-Anon, a service that helps relatives facilitate the recovery journey. In this way, it is hoped that firms and organizations can offer superior value propositions that help customers achieve their goals (Epp and Price, 2011).

Finally, firms and organizations need to recognize that, when considering the consumer's higher-order goals, negative experiences can be beneficial for the consumer's goal pursuit since they can drive behavior. Thinking about how the customer experience influences the goal pursuit - instead of simply trying to offer positive experiences - offers a new, more complex perspective for firms and organizations. For example, clinics and treatment centers might offer better services if they help their customers face their problems. This process invariably involves negative experiences that are beneficial when considering the consumer's higher-order goal.

\subsection{Limitations and suggestions for future research}

This paper's main limitation is that the phenomenological study was restricted to a specific case of a transformative journey. While the extreme context enables conceptual development, its characteristics might delimit generalizing the results to other service contexts. These results might generalize easily to other cases of transformative journeys, such as smoking cessation and adoption of a healthier lifestyle. However, it is expected that the developed model and its implications can be useful for analyzing other types of goal-oriented journeys as each journey comprises cognitive and behavioral processes related to how consumers pursue their goals, be it higher-order goals such as health or lower-order goals such as buying groceries. As Carver and Scheier (1998, p. 63) noted, "life is a continual process of establishing goals and adjusting patterns of behavior to match those goals more closely, using informational feedback as a guide." Future studies should assess the applicability of these findings to other contexts, such as a pregnancy journey, dealing with a disease or a journey toward a successful career.

\section{A goal-oriented view of customer journeys}


JOSM 31,4

788

The second limitation relates to how participants were recruited. As all participants were AA members, the findings may overestimate the importance of self-help groups and the 12step program. In future studies, researchers might investigate a goal-oriented journey that relies less on engaging with one particular type of service.

In terms of future research avenues, the positive effect of some negative experiences in relation to the goal is a counterintuitive finding that warrants further attention. Future research should examine the extent to which negative experiences drive long-term positive outcomes or represent a form of cognitive dissonance. Future studies should also seek to clarify the relationship between the customer experience and value-in-use, defined as the perceived consequences of goal achievement (Macdonald et al., 2016) as the existing literature tends to treat these variables as being positively correlated (e.g. Sandström et al., 2008). From the findings, this relationship appears more complex in the case of transformative journeys, where negative experiences possibly contribute to value-in-use.

The goal-oriented view also highlights the importance of examining interrelations between different customer journeys: a particular customer journey might be significantly affected by another journey that can provide obstacles or support in terms of the higher-order goal. The multilayered view depicted in Figure 3 brings a broader perspective to relevant contextual factors, explaining why customers might respond differently to stimuli at individual touchpoints (cf. Becker and Jaakkola, 2020). Extant literature has predominantly focused on customer journeys with a single offering, but viewing touchpoints as embedded in the broader context of consumer journeys could help identify new antecedents and contingencies for the customer experience and its evaluative outcomes.

\section{Note}

1. A detailed account of data collection and analysis is provided in a web appendix.

\section{References}

Akaka, M.A. and Vargo, S.L. (2015), "Extending the context of service: from encounters to ecosystems", Journal of Services Marketing, Vol. 29 Nos 6/7, pp. 453-462, doi: 10.1108/JSM-032015-0126.

Austin, J.T. and Vancouver, J.B. (1996), "Goal constructs in psychology: structure, process, and content”, Psychological Bulletin, Vol. 120 No. 3, pp. 338-375, doi: 10.1037/0033-2909.120.3.338.

Baron, S. and Harris, K. (2010), "Toward an understanding of consumer perspectives on experiences", Journal of Services Marketing, Vol. 24 No. 7, pp. 518-531, doi: 10.1108/08876041011081078.

Becker, L. and Jaakkola, E. (2020), "Customer experience: fundamental premises and implications for research", Journal of the Academy of Marketing Science, Vol. 48, pp. 630-648, doi: 10.1007/ s11747-019-00718-x.

Bevan, M.T. (2014), "A method of phenomenological interviewing”, Advancing Qualitative Methods, Vol. 24 No. 1, pp. 136-144, doi: 10.1177/1049732313519710.

Brakus, J.J., Schmitt, B.H. and Zarantonello, L. (2009), "Brand experience: what is it? How is it measured? Does it affect loyalty?", Journal of Marketing, Vol. 73, pp. 52-68, doi: 10.1509/jmkg.73.3.052.

Carú, A. and Cova, B. (2008), "Small versus big stories in framing consumption experiences", Qualitative Market Research: An International Journal, Vol. 11 No. 2, pp. 166-176, doi: 10.1108/ 13522750810864422.

Carver, C.S. and Scheier, M.F. (1982), "Control theory: a useful conceptual framework for personalitysocial, clinical, and health psychology", Psychological Bulletin, Vol. 92 No. 1, pp. 111-135, doi: 10. 1037/0033-2909.92.1.111.

Carver, C.S. and Scheier, M.F. (1990), "Origins and functions of positive and negative affect: a controlprocess view”, Psychological Review, Vol. 97 No. 1, pp. 19-35, doi: 10.1037/0033-295X.97.1.19. 

Carver, C.S. and Scheier, M.F. (1998), On the Self-Regulation of Behavior, Cambridge University Press, A goal-oriented
New York.

Creswell, J.W. (2013), Qualitative Inquiry and Research Design: Choosing Among Five Approaches, 3rd ed., SAGE, Thousand Oaks, CA.

Edelman, D.C. and Singer, M. (2015), "Competing on customer journeys”, Harvard Business Review, Vol. 93, pp. 88-100.

Epp, A.M. and Price, L.L. (2011), "Designing solutions around customer network identity goals", Journal of Marketing, Vol. 75, pp. 36-54, doi: 10.1509/jm.75.2.36.

Følstad, A. and Kvale, K. (2018), "Customer journeys: a systematic literature review", Journal of Service Theory and Practice, Vol. 28 No. 2, pp. 196-227, doi: 10.1108/JSTP-11-2014-0261.

Goulding, C. (2005), "Grounded theory, ethnography and phenomenology: a comparative analysis of three qualitative strategies for marketing research", European Journal of Marketing, Vol. 39 Nos 3/4, pp. 294-308, doi: 10.1108/03090560510581782.

Grönroos, C. and Ravald, A. (2011), "Service as business logic: implications for value creation and marketing", Journal of Service Management, Vol. 22 No. 1, pp. 5-22, doi: 10.1108/ 09564231111106893.

Halvorsrud, R., Kvale, K. and Følstad, A. (2016), "Improving service quality through customer journey analysis", Journal of Service Theory and Practice, Vol. 26 No. 6, pp. 840-867, doi: 10.1108/JSTP05-2015-0111.

Hamilton, R. and Price, L.L. (2019), "Consumer journeys: developing consumer-based strategy", Journal of the Academy of Marketing Science, Vol. 47 No. 2, pp. 187-191, doi: 10.1007/s11747-01900636-y.

Heinonen, K. and Strandvik, T. (2015), "Customer-dominant logic: foundations and implications", Journal of Services Marketing, Vol. 29 Nos 6/7, pp. 472-484, doi: 10.1108/JSM-02-2015-0096.

Heinonen, K., Strandvik, T., Mickelsson, K., Edvardsson, B., Sundström, E. and Andersson, P. (2010), "A customer-dominant logic of service", Journal of Service Management, Vol. 21 No. 4, pp. 531-548, doi: 10.1108/09564231011066088.

Horrigan-Kelly, M., Millar, M. and Dowling, M. (2016), "Understanding the key tenets of Heidegger's philosophy for interpretive phenomenological research", International Journal of Qualitative Methods, Vol. 15 No. 1, pp. 1-8, doi: 10.1177/1609406916680634.

Jaakkola, E., Helkkula, A. and Aarikka-Stenroos, L. (2015), "Service experience co-creation: conceptualization, implications, and future research directions", Journal of Service Management, Vol. 26 No. 2, pp. 182-205, doi: 10.1108/JOSM-12-2014-0323.

Kranzbühler, A., Kleijnen, M.H.P., Morgan, R.E. and Teerling, M. (2018), "The multilevel nature of customer experience research: an integrative review and research agenda", International Journal of Management Reviews, Vol. 20, pp. 433-456, doi: 10.1108/JOSM-12-2014-0323.

Kuehnl, C., Jozic, D. and Homburg, C. (2019), "Effective customer journey design: consumers' conception, measurement, and consequences", Journal of the Academy of Marketing Science, Vol. 47 No. 3, pp. 551-568, doi: 10.1007/s11747-018-00625-7.

Lemon, K.N. and Verhoef, P.C. (2016), "Understanding customer experience throughout the customer journey”, Journal of Marketing, Vol. 80, pp. 69-96, doi: 10.1509/jm.15.0420.

Lipkin, M. (2016), “Customer experience formation in today's service landscape”, Journal of Service Management, Vol. 27 No. 5, pp. 678-703, doi: 10.1108/JOSM-06-2015-0180.

Macdonald, E.M., Kleinaltenkamp, M. and Wilson, H.N. (2016), "How business customers judge solutions: solution quality and value in use", Journal of Marketing, Vol. 80, pp. 96-120, doi: 10. 1509/jm.15.0109.

McColl-Kennedy, J.R., Gustafsson, A., Jaakkola, E., Klaus, P., Radnor, Z.J., Perks, H. and Friman, M. (2015), "Fresh perspectives on customer experience", Journal of Services Marketing, Vol. 29 Nos 6/7, pp. 430-435, doi: 10.1108/JSM-01-2015-0054. 
JOSM 31,4
Patrício, L., Fisk, R.P., Falcão e Cunha, J. and Constantine, L. (2011), "Multilevel service design: from customer value constellation to service experience blueprinting", Journal of Service Research, Vol. 14 No. 2, pp. 180-200, doi: 10.1177/1094670511401901.

Powers, W.T. (1973), “Feedback: beyond behaviorism”, Science, Vol. 179 No. 4071, pp. 351-356, doi: 10. 1126/science.179.4071.351.

Sandström, S., Edvardsson, B., Kristensson, P. and Magnusson, P. (2008), "Value in use through service experience", Managing Service Quality, Vol. 18 No. 2, pp. 112-126, doi: 10.1108/ 09604520810859184.

Tax, S.S., McCutcheon, D. and Wilkinson, I.F. (2013), "The service delivery network (SDN): a customercentric perspective of the customer journey", Journal of Service Research, Vol. 16 No. 4, pp. 454-470, doi: 10.1177/1094670513481108.

Teixeira, J., Patrício, L., Nunes, N.J., Nóbrega, L., Fisk, R.P. and Constantine, L. (2012), "Customer experience modeling: from customer experience to service design", Journal of Service Management, Vol. 23 No. 3, pp. 362-376, doi: 10.1108/09564231211248453.

Thompson, C.J., Locander, W.B. and Polio, H.R. (1989), "Putting consumer experience back into consumer research: the philosophy and method of existential-phenomenology", Journal of Consumer Research, Vol. 16 No. 2, pp. 133-146, doi: 10.1086/209203.

Vargo, S.L. and Lusch, R.F. (2008), "Service-dominant logic: continuing the evolution", Journal of the Academy of Marketing Science, Vol. 36, pp. 1-10, doi: 10.1007/s11747-007-0069-6.

Zomerdijk, L.G. and Voss, C.A. (2010), "Service design for experience-centric services", Journal of Service Research, Vol. 13 No. 1, pp. 67-82, doi: 10.1177/1094670509351960.

\section{Supplementary material}

Supplementary material is available for this article.

\section{About the authors}

Dr. Larissa Becker is a postdoctoral researcher in marketing at the Turku School of Economics, University of Turku, Finland. Her research interests are customer experience, customer and consumer journeys, service-dominant logic and compulsive consumption. She has published articles in journals such as Journal of the Academy of Marketing Science, Qualitative Market Research: An International Journal, Journal of Research in Interactive Marketing and Journal of Retailing and Consumer Services. Larissa Becker is the corresponding author and can be contacted at: larissa.c.brazbecker@utu.fi

Dr. Elina Jaakkola is Professor of Marketing at the Turku School of Economics, University of Turku, Finland. Her research interests focus on value creation, customer/actor engagement, customer experience, service innovation and knowledge-intensive business services and solutions. Her research articles have been published in a wide range of journals and book chapters, for example, Journal of the Academy of Marketing Science, Journal of Product Innovation Management, Journal of Service Research, Industrial Marketing Management, Journal of Business Research, Journal of Service Management and Marketing Theory.

Dr. Aino Halinen is Professor of Marketing at the Turku School of Economics, University of Turku, Finland. She has published articles on professional service marketing, relationship management, business network dynamics and qualitative methods, especially process and case research, in a number of journals such as Journal of Management Studies, Industrial Marketing Management, Journal of Business Research and Journal of Service Management. Her current research work focuses on research paradigms in business-to-business (B2B) marketing and visioning in business networks.

For instructions on how to order reprints of this article, please visit our website:

www.emeraldgrouppublishing.com/licensing/reprints.htm

Or contact us for further details: permissions@emeraldinsight.com 